\title{
Formic Acid Formation from the Electrochemical Reduction of Carbon Dioxide Catalyzed by a Rhodium Protoporphyrin in aqueous solution
}

\author{
Jing Shen", Kunxiang Deng, Xiangjun Li, Donghui Lan", Zhengjun Fang \\ Hunan Provincial Key Laboratory of Environmental Catalysis \& Waste Recycling, School of Material \\ and Chemical Engineering, Hunan Institute of Engineering, Xiangtan, 411104, P.R. China. \\ *E-mail: jingshen84@ sina.com, donghuilan@hnu.edu.cn
}

Received: 28 May 2021 / Accepted: 13 July 2021 / Published: 10 August 2021

\begin{abstract}
The electrochemical conversion of $\mathrm{CO}_{2}$ into valuable fuels is a promising technique to store intermittent energy, such as wind, solar and nuclear, and facilitate a closed carbon cycle. Here we report the formation of formic acid from the electrochemical reduction of $\mathrm{CO}_{2}$ catalyzed by rhodium-protoporphyrin in aqueous solution. The formation of formic acid is highly dependent on $\mathrm{pH}$ with the highest faradaic efficiency of $50 \%$ at $\mathrm{pH}=3$ while it is negligible at $\mathrm{pH}=1$. The theoretical predication indicates that $\mathrm{CO}$ should be the main product from the electrochemical reduction of $\mathrm{CO}_{2}$ catalyzed by rhodiumprotoporphyrin as cobalt-protoporphyrin. However, the strong affinity of axial ligands hinders the formation of metal-bonded carboxylate or metal-hydride intermediates leading to the difficulty of the formation of $\mathrm{CO}$ or formic acid through the intermediate respectively. The most likely intermediate for the formation of formic acid catalyzed by rhodium-protoporphyrin is phlorin-hydride which is an intermediate protonated the meso carbon of the macrocycle.
\end{abstract}

Keywords: rhodium-protoporphyrin; $\mathrm{CO}_{2}$ electrochemical reduction; formic acid; phlorin-hydride

\section{FULL TEXT}

(C) 2021 The Authors. Published by ESG (www.electrochemsci.org). This article is an open access article distributed under the terms and conditions of the Creative Commons Attribution license (http://creativecommons.org/licenses/by/4.0/). 